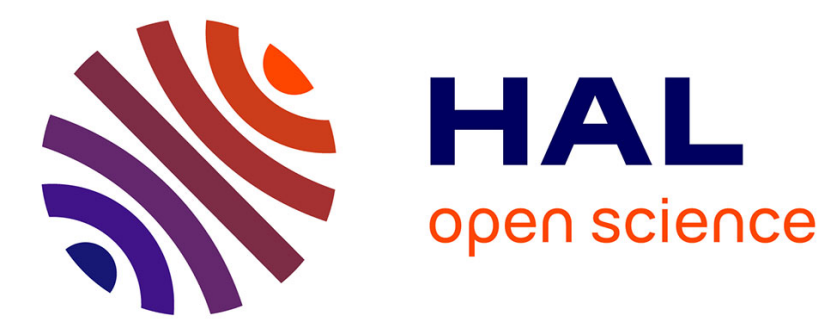

\title{
Habeas Corpus: The Sense of Ownership of One's Own Body
}

Frédérique de Vignemont

\section{To cite this version:}

Frédérique de Vignemont. Habeas Corpus: The Sense of Ownership of One 's Own Body. Mind and Language, 2007, pp.427-449. ijn_00169860

\section{HAL Id: ijn_00169860 \\ https://hal.science/ijn_00169860}

Submitted on 5 Sep 2007

HAL is a multi-disciplinary open access archive for the deposit and dissemination of scientific research documents, whether they are published or not. The documents may come from teaching and research institutions in France or abroad, or from public or private research centers.
L'archive ouverte pluridisciplinaire HAL, est destinée au dépôt et à la diffusion de documents scientifiques de niveau recherche, publiés ou non, émanant des établissements d'enseignement et de recherche français ou étrangers, des laboratoires publics ou privés. 


\title{
Habeas Corpus: The Sense of Ownership of One's Own Body
}

\author{
FREDERIQUE DE VIGNEMONT
}

\begin{abstract}
What grounds my experience of my body as my own? The body that one experiences is always one's own, but it does not follow that one always experiences it as one's own. One might even feel that a body part does not belong to oneself despite feeling sensations in it, like in asomatognosia. The article aims at understanding the link between bodily sensations and the sense of ownership by investigating the role played by the body schema.
\end{abstract}

'Merely-you are my own nose.'

The Nose regarded the major and contracted its brows a little.

'My dear sir, you speak in error' was its reply. 'I am just myself-myself separately.'

Gogol (1835)

The body has an ambiguous status, as it seems to be both what we are and what belongs to us. The study of the relationship between the body and the self raises several distinct issues. First, there is the question of personal identity: would the prince be the same person if he had the cobbler's body? Second, there is the question of the nature of the self: is the self only mental or also bodily? Third, there is the question of the sense of ownership: on which basis do I feel this body as my own? In this paper, I shall focus on the last question by investigating the conditions of possibility of the sense of ownership of one's own body.

It may seem as if it was nonsensical to ask whether you are sure that this is your own body. The body that you feel is necessarily your own body. However, this does not imply that you necessarily experience the body that you feel as your own. Indeed, some patients suffering from asomatognosia feel their own limb as alien, despite having tactile sensations in the 'alien' limb. How can we account for such phenomenon? After reviewing different possibilities, I will argue for a spatial view of the sense of ownership that emphasizes the multimodal nature of the spatial representation of the body as well as its functional significance for action.

I would like to thank the Mind $\&$ Language reviewers as well as Roblin Meeks and Tim Bayne for their helpful comments. This work was finished with the help of the ARC International Linkage Award Grant.

Address for correspondence: Institut Jean-Nicod, 29 rue d'Ulm, 75005 Paris, France.

Email: fvignemont@isc.cnrs.fr 


\section{Disownership and Ownership}

Examiner: Whose arm is this?

A.R: It's not mine.

Ex: Whose is it?

A.R: It's my mother's.

Ex: How on earth does it happen to be there?

A.R I don't know. I found it in my bed.

Ex: How long has it been there?

A.R: Since the first day. Feel, it's warmer than mine. The other day too, when the weather was colder, it was warmer than mine.

Ex: So, where is your left arm?

A.R: It's under there (indefinite gesture forwards) (Bisiach et al., 1991, p. 1030)

\subsection{A Sense of Disownership}

Following a lesion of the right hemisphere, A.R suffers from somatoparaphrenia. She denies that her own arm belongs to her. In 1931, Guttmann already described a patient with a right parietal head injury who developed a generalized seizure preceded by 'a feeling as if his left hand did not belong to him any longer ... that this hand was completely foreign and belonged to another person' (Feinberg et al., 1998). However, it is only with Brion and Jedynak in 1972 that the phenomenon of 'main étrangère' was tagged as such. They defined it as a 'feeling of estrangement between the patient and one of his hands'. Since then, there has been a widespread confusion in the literature between the Alien Hand and the Anarchic Hand, which are both often coined under the single term of 'Alien Hand Sign' (Marchetti and Della Salla, 1998). The Anarchic Hand refers to the experience of autonomous semi-purposeful movements of the arm, which are experienced as alien to the patient's volition. The Alien Hand refers to a sense of disownership towards one's own hand. Roughly speaking, the former is a disorder of action awareness; the latter is a disorder of body awareness. Some patients display both syndromes (Feinberg et al., 1998), but others not: their hand may feel 'anarchic', but they still feel it as their own hand. In this paper, I shall focus on the Alien Hand. In order to avoid any confusion, I will use the term 'asomatognosia' to refer to the sense of disownership towards one's own limb following a lesion of the right hemisphere.

Forms of disownership can be encountered in various cases. First, as previously described, it can occur following a brain lesion or an epileptic seizure in the parietal lobe of the right hemisphere (Feinberg, 2002). It is then often associated with neglect of the external space and the bodily space (also called 'personal neglect'), somatosensory deficits, hemiplegia, anosognosia and Anarchic hand. However, as we will see later in more detail, asomatognosia cannot be reduced to any of these disorders (Moro et al., 2004). Cases of sense of disownership have also been 
reported following peripheral nerves disruption, like brachial plexus injury (Sacks, 1991), deafferentation (Cole, 1995) or local anaesthesia (Paqueron et al., 2003). Finally, feelings of disownership have been reported during psychiatric episodes. People suffering from depersonalization disorder feel the external world and their own body as unreal. More particularly, they complain about abnormal bodily experiences. Among them, they report 'a lack of body ownership feelings' (Sierra et al., 2005). This feeling may also explain the very surprising Body Integrity Identity Disorder (BIID). Individuals with BIID ask to have their healthy limbs amputated and they feel relieved when they have gone through surgery. One of the reasons that they mention is that the limb felt like it was not their own. However, other factors may also intervene in their decision (Bayne and Levy, 2005).

Are all these forms of disownership identical? It is difficult to say, given that we have access only to the patients' introspective reports. There are differences relative to the 'alien' body part: denial of the limbs (particularly the upper limbs) and their extremities is most frequent, but the whole body can be affected, as occurs in deafferented patients and in patients with depersonalization disorder. There are also differences relative to the affective attitude toward the 'alien' limb. While individuals with BIID want to cut it off, some asomatognosic patients view it as a 'buddy' (Feinberg et al., 1998). Finally, patients differ in attributing or not the 'alien' limb to someone else or in even personifying it (e.g. 'a mind of its own', in Leiguarda et al., 1993). This difference partly reflects the distinction between neurological patients (who attribute their limb to someone else, quite often to the examiner, but also to relatives, although they are not in the room) and psychiatric patients (who rarely attribute their limb to other people). This difference may also depend on the underlying cause of the sense of disownership. We can account for the feeling of disownership either by some additional features of bodily experiences indicating alienness or by the lack of features indicating ownership. In addition, the level at which the denial arises may differ. There are three possible scenarios leading to the sense of disownership of one's own limb.

(a) Patients experience their limb as alien, but they still believe that it belongs to them (Sacks, 1991; Cole, 1995).

(b) Patients experience their limb as alien and they believe that it does not belong to them. They attribute it to someone else (Feinberg et al., 1998; Schiff and Pulver, 1999). ${ }^{1}$

(c) Patients experience their limb as their own, but despite that, they believe that it does not belong to them.

1 Some patients with asomatognosia attribute ownership to someone else, but they can be quickly corrected. Other patients maintain their delusional belief despite correction. For instance, Mirna cannot be convinced that this is her own hand: 'Feinberg: Suppose I told you this was your hand? Mirna: I wouldn't believe you' (Feinberg et al., 2005, p. 104). 
A sense of disownership can thus occur either at the phenomenological level or at the doxastic level or at both. In (a) and (c), patients do not take their own bodily experiences at face value, because they are overridden by other factors. This shows the complexity of the processing underlying the recognition of one's own limbs. One may be entitled to believe that this hand is one's own independently of what one feels. For instance, the spatial contiguity of the 'alien' limb with the rest of one's own body may suffice to justify the belief that this is one's own hand even if it does not feel like it. Body recognition is then inferred from sources of knowledge about the body (e.g. spatial contiguity), rather than directly based on bodily experiences. ${ }^{2}$

I shall try here to understand how someone can feel his own hand as alien, but for that, I need to use pathologies in which people report that their limbs feel alien as data. Presumably, it is often the case that people who believe that their limbs are no longer their own do so because they experience them as alien. I will also limit myself mainly to asomatognosia, although even with the previous restrictions, asomatognosia remains open to different interpretations. I will assume here that the lesion leading to asomatognosia deprives the subject of some key features indicating ownership. But what is missing?

\subsection{A Sense of Ownership}

Intuitively, one would like to reply that what is missing is the sense of ownership, that is, the awareness of the body as one's own. However, this reply is not very informative. What are the specific features that specify that this is one's own body? And what is it to feel this body as one's own? The existence of a positive phenomenology of ownership is not obvious. At the doxastic level, the description of my bodily sensations includes a first-person component ( $m y$ hand is burning). ${ }^{3}$ But do I really experience that this is $m y$ hand?

Even if there was no first-person component included in the content of bodily sensations, it does not imply that there is no sense of ownership provided by sensations. It would not be surprising that the sense of ownership was dim and elusive. The body stays indeed most of the time at the margin of consciousness (Gurwitsch,

2 I am not interested here in this kind of ownership judgments, as they are disconnected from the experience of ownership. See Marcel (2003) for an analysis of the different levels of self-attribution. My interest here is limited to what he calls 'minimal self-recognition' and its experiential ground.

3 Interestingly, the first-person possessive term differs in some languages whether it concerns an inalienable body part (e.g. my head, which will always be mine) or an alienable object (e.g. my car, which can be sold). In addition, it is worth noticing that some languages make the distinction between different degrees of possession for body parts themselves. For instance, in Kilivila (the Australasian language of the Trobriand Islanders), proper body parts like arms or legs are always associated with a possessive pronominal suffix indicating a degree of intimate possession, while internal organs are associated with a possessive term indicating a more distant possession (Senft, 1998). 
1985). You rarely focus your attention on it. While typing on your laptop, you do not vividly experience your fingers on the keyboard. Your conscious field is mainly occupied by the content of what you are typing. You do not feel that these are your own fingers. The phenomenology of the body is often recessive, except during intensely pleasant or unpleasant sensations. Yet, there are three sources of evidence, which suggest that there is a sense of ownership.

Imagine the following situation. You close your eyes and someone takes your hand. Nothing in your experience tells you who is holding your hand. Yet, you feel this anonymous hand holding your own hand and nobody else's hand. There seems to be a phenomenological difference between your experience of someone else's hand and your experience of your own hand, which could be explained by a sense of ownership.

Let us now see what happens when you see someone being touched. You are able to directly (non-inferentially) compare what she feels with what you would feel if you were touched. Indeed, it has been shown recently that observing someone being touched partially elicits the same activation in the somatosensory cortex in the observer as if the observer was being touched at the same location (Keysers et al., 2004). Even more surprisingly, a woman reported feeling tactile sensations on her own skin when observing another person being touched (Blakemore et al., 2005). Similarly, it was shown that observing pain in others partially activates the same neural network as that when experiencing pain (Singer et al., 2004). In addition, it elicits the same muscle response (Avenanti et al., 2005). Given this 'transparency of bodily experiences', we can immediately recognize that we feel the same by a kind of empathy (Dokic, 2003). However, the mapping between self and other does not lead to a confusion between self and other. We do not confuse our sensations with someone else's sensations, nor do we feel our own sensations in someone else's body parts. Because representations of bodily sensations are shared between self and other, one needs to be able to differentiate one's own body and someone else's body (Decety and Jackson, 2004). The sense of ownership results from this differentiation.

A final source of evidence comes from introspective reports of amputees wearing prosthesis. People have more or less difficulty in accepting prosthesis and in integrating them in their body representation. Yet, some of them acquire a strong feeling of ownership toward their prosthesis, as shown by the following example:

Many amputees feel that their artificial limb is somehow part of them, a simple example of this is that I wouldn't like just anyone putting their hand on my artificial knee, even though it is not actually part of my body's flesh, it is still mine even though it's a piece of plastic and metal (Murray, 2004, p. 970)

We can make sense of the difference between amputees who feel their artificial limb as their own body part and those who do not by the presence of a sense of ownership. Interestingly, the embodiment of the prosthesis plays a central 
role in the successful adaptation of the amputees to their new limb (Murray, 2004).

I have argued here for the existence of a positive phenomenology of the sense of ownership, even if recessive most of the time. We need now to understand what it consists in.

\section{Bodily Sensations and the Sense of Ownership}

Dokic (2003) suggests the following basic specification of the general form of bodily experiences:

'Experience (a particular body part is F)'.

The content of this experience-described inside the brackets-includes two components: the descriptive content that represents the bodily property $\mathrm{F}$ and the spatial content that assigns a specific location within a body part to the bodily property (Bermúdez, 1998). Besides some general unspecific sensations such as hunger or tiredness, bodily properties are localized in a specific body part. This description can apply both to the first-person and to the third-person perspective, as required by the transparency view. However, there is nothing in such content that tells us whose body part is represented. What is the ground of the sense of ownership?

\subsection{A General Panoptic}

Given the transparency of bodily experiences, what makes the difference between my hand being touched and me seeing your hand being touched? It is time now to provide a theoretical panoptic of the different views about the sense of ownership (see Dokic, 2003). The main question that we need to address is whether the sense of ownership is given by bodily sensations. If we reply no to the question, then the sense of ownership consists in an additional quality, which may depend at the subpersonal level on a specific mechanism of self-attribution. If we reply yes to the question, then the sense of ownership derives from bodily sensations. But what in bodily sensations gives the sense of ownership? It may be the way we have access to the body through bodily sensations, in contrast with external perception (e.g. I feel versus I see that the legs are crossed). Or it may be the content of bodily sensations (e.g. the legs are crossed). In the latter case, the question is what in the content of bodily sensations gives the sense of ownership. It may be the descriptive component of the content, that is, the bodily property that is experienced (e.g. being crossed). Alternatively, it may be its mode of presentation, that is, the way the bodily property is represented (e.g. being crossed visually perceived versus proprioceptively felt). Or it may be the spatial component of the content that assigns a specific location to the bodily property (e.g. the legs). We have thus five hypotheses that I will sum up as follows: 


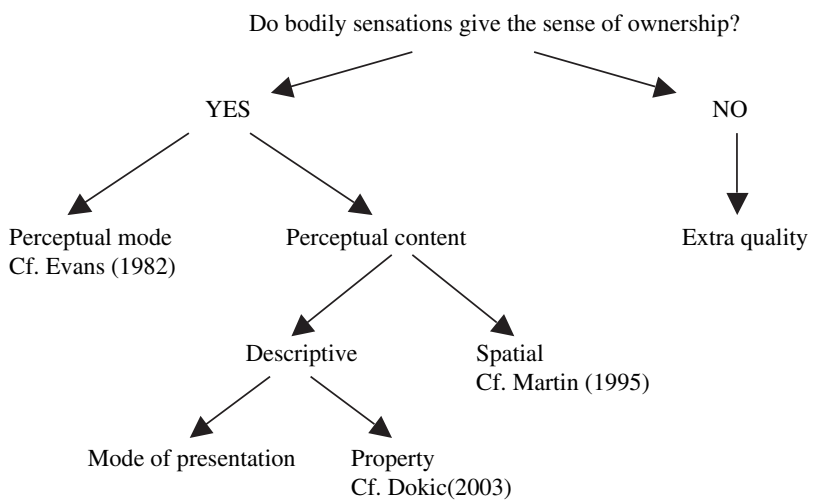

Figure 1 Panoptic of different views about the sense of ownership

\subsection{How to Account for Asomatognosia}

Can asomatognosia settle the debate? By looking at the circumstances when the sense of ownership is missing, we will acquire a better understanding of what gives us the sense of ownership. A way to test the different hypotheses is to ask if individuals with asomatognosia have still bodily sensations in the affected limb and if these sensations differ from the sensations they have in the non-affected limb.

One could suggest that the sense of disownership is explained by the loss of bodily sensations. Interestingly, asomatognosia is frequently associated with hemianaesthesia and neglect. Personal neglect is so often associated with asomatognosia that they even have been taken as synonymous. For instance, they both diminish after vestibular stimulation (Bisiach et al., 1991; Schiff and Pulver, 1999). However, the relation between bodily sensations and the sense of ownership is far more complex, as shown by the following experiments. First, somatosensory anaesthesia does not necessarily lead to the lack of the sense of ownership. In a study with normal subjects who have been locally anaesthetized, only 5 out of 36 subjects denied the ownership of their limb (Paqueron et al., 2003). These persons were still able to correctly perceive the position of the limb while blindfolded. It shows that they still have access to proprioceptive information. However, the question here is not whether somatosensory information provides the sense of ownership, but rather whether somatosensory experiences do it. More interesting is the case of AF and SB (Moro et al., 2004). These two patients had a lesion of the right hemisphere. They suffered from neglect, hemiplegia, proprioceptive and tactile deficits and asomatognosia of the left upper limb. It has been shown that positioning the neglected left hand in the non-neglected right hemispace decreases attentional neglect (Aglioti et al., 1999). Moro and collaborators investigated whether it could also improve asomatognosia. As predicted, they showed that the patients were able to feel tactile sensations in the left arm when the left arm was located in the right hemispace (which was not neglected). However, despite feeling 
that they were touched, AF and SB still felt their left arm as alien. When asked how it was possible to perceive in someone else's hand, AF replied that 'many strange things can happen in life' (Moro et al., 2004, p. 440). However, when asked about the ownership of his intact hand, SB replied 'it would be strange to feel others' body parts as one's own' (Moro et al., 2004, p. 441). ${ }^{4}$

These results are counterintuitive. As SB said, how could one perceive from the inside someone else's body parts? Nevertheless, they provide a clear dissociation between tactile sensations and sense of ownership. Patients can experience a bodily property localized in a body part that they feel as alien. I take at face value the subjects' introspective reports and I would like to assume here that this dissociation occurs at the phenomenological level, and not at the doxastic level. If this is the case, then what does it tell us about the sense of ownership?

A first way to interpret these results, which I will not endorse, is to claim that bodily sensations do not provide the sense of ownership. We have seen indeed that people can still feel their limb as their own while being anaesthetized (Paqueron et al., 2003). However, one may reply that bodily sensations may be sufficient, although not necessary for the sense of ownership. More challenging is the fact that one could have bodily sensations felt in a certain body part without feeling this body part as one's own. Does it mean that the sense of ownership consists in an additional quality 'over and above' bodily experiences? The first problem with this hypothesis is that we do not know on what ground the extra quality of ownership would be based. But more fundamentally, we are not entitled to draw such a radical conclusion on the sole basis of these results. We previously distinguished between different aspects of bodily sensations that may account for the sense of ownership. Some aspects may be challenged by these results, but not necessarily all of them.

The presence of bodily sensations in the 'alien' hand refutes the view that the sense of ownership is provided by the perceptual mode of bodily sensations. I want to argue that the perceptual mode of AF's and SB's sensations does not differ when their 'alien' hand is touched and when their 'owned' hand is touched. In both cases, they receive the same kinds of information (no visual input, only tactile inputs). Furthermore, this is not a case of 'numbsense' where subjects process tactile information, but have no perceptual experience associated with their processing (Rossetti et al., 1995). Here, they consciously felt the touch in both hands, with 100\% accuracy. One may still argue that their tactile experience remained abnormal for the left hand, which would explain their feeling of disownership. However, AF and SB did not report any difference in their tactile

4 Other similar cases have been reported in the literature. Melzack (1990) described a patient who screamed when the examiner squeezed his 'alien' hand, but who still denied that this hand belonged to him. Bottini et al. (2002) also reported a case of an asomatognosic patient who was unable to report touches delivered on her left hand and who attributed it to her niece. When told that she would be touched on the left hand, she said she felt nothing. However, when told that she would be touched on her niece's hand, her tactile anaesthesia completely recovered. This surprising result is interesting, but difficult to interpret. 
experience. In addition, other patients have similarly recovered from tactile extinction by changing the position of their hand, without denying the ownership of their hand (Smania and Aglioti, 1995). It thus seems accurate to claim that AF and SB had similar tactile experiences for both hands. Despite that, they did not feel the hand as their own in one case, while they did in the other case. Consequently, I claim that the perceptual mode of bodily sensations does not suffice to provide the sense of ownership.

However, the lack of sense of ownership may be explained by differences at the level of the content of bodily sensations. Again, there seems to be no salient difference for the descriptive component of the content. More particularly, the felt property is the same in both cases. As for the mode of presentation, it does not seem a plausible candidate for independent reasons. Let us imagine that the same bodily property could be presented under the mode $M$ 'from the inside' and under the mode M' 'from the outside' and that they are not intensionally transparent. Consequently, I would not necessarily know that my bodily condition under the mode $\mathrm{M}$ is identical to yours under the mode $\mathrm{M}^{\prime}$ in the same way that I do not necessarily know that Hesperus refers to the same planet as Phosphorus (Dokic, 2003). If so, bodily experiences could not be immediately recognized as shared. In other words, they would not be transparent. This possibility goes against the hypothesis of shared representations of bodily sensations (Keysers et al., 2004; Singer et al., 2004; Decety and Jackson, 2004). Therefore, we should reject modes of presentation of bodily properties analogous to Fregean modes of presentation. Consequently, the mode of presentation of bodily sensations cannot be the basis of the sense of ownership.

To sum up, the descriptive content of the sensations felt in the 'alien' hand cannot account for the lack of sense of ownership. On the one hand, the property that is felt in the 'alien' hand and in the 'owned' hand is the same. On the other hand, there is no difference between modes of presentation as it would prevent the transparency of bodily experiences.

The spatial component is all that remains. At this level, there is obviously a difference. The tactile sensation is felt either in the right hand (owned) or in the left hand (alien). The point here is not that it is a right or a left hand. It is rather that the bodily property is ascribed to a specific location within the spatial representation of the body. One may therefore suggest that the content of bodily sensations in the 'alien' hand is different because the spatial representation where the body part is located is different. I will from now on analyse the validity of what I shall call the Spatial Hypothesis: the sense of ownership derives from the spatial representation of the body.

\section{The Spatial Hypothesis}

Ayer (1963) suggested that bodily sensations define the boundaries of one's own body: 
... it is a defining property of 'my' body to be the locus of my organic sensations. This would not entail that these sensations could never be located outside my body, but only that any human body in which they were located would necessarily be mine (Ayer, 1963, p. 55).

He described here what Dokic (2003) calls 'the fact of ownership' (why bodily sensations are necessarily about one's own body), rather than the sense of ownership (why I experience the body parts that I feel as mine). Martin (1995) provides a more interesting view. He reduces the sense of ownership to the sense of the boundaries of one's own body. The spatial structure of bodily sensations is such that sensations are necessarily experienced within the boundaries of one's own body. Indeed, in bodily experiences, there is nothing that does not fall within the limits of the somatosensory field. In contrast, the boundaries of the object that I see are not co-extensive with the visual field. However, Martin does not go into detail about the delineation of the boundaries of one's own body.

I will now investigate the nature of the spatial representation of the body that underlies the sense of ownership. I assume the existence of a mental representation of the spatial disposition and relationship between the various parts of the body and the whole. The spatial representation of the body has to be distinguished from the objective physical body (Merleau-Ponty, 1945). Body representations do not constitute a complete and accurate display of the body in our mind. For instance, one's body representations may represent one's own hand despite its amputation, as in the phantom limb phenomenon. Conversely, they may also omit one side of the body, as in personal neglect. I will now review the different sources of information that contribute to the spatial representation of the body. Perhaps we can determine how the boundaries of the self are represented by determining how the boundaries of the body are represented.

\subsection{A Multimodal Spatial Representation of the Body}

Martin assumes that bodily sensations are felt within the boundaries of the somatosensory representation of the body. However, this view does not account for the way one's own body is spatially represented. Indeed, it relies on the assumption that bodily experiences are purely unimodal. This view can be tracked down to the modular architecture of the mind as postulated by Fodor (1983): the first levels of processing of sensory stimuli are encapsulated, isolated from the influence of any other kind of information. However, recent experimental data about cross-modal effects suggest that this view is no longer sustainable (Spence and Driver, 2004). We cannot reduce the representation of one's own body to a purely somatosensory representation and neglect the preponderant role of visual information. Tactile stimuli are remapped into a visual frame of reference because of the dominant role of vision in action. Thus, the spatial content of tactile sensations is not only relative to the skin, but also relative to the current disposition of the body part that has been touched, as given by vision and proprioception. 
Recent experimental results have shown that (1) bodily experiences are based on multimodal representation of the body and (2) even the primary stages of the somatosensory processing are affected by other kinds of information such that there is never a 'pure' somatosensory field. ${ }^{5}$ I review here three examples that provide evidence of the existence of a multimodal representation of the body (for more evidence, see Gallagher, 2005).

Visual enhancement of spatial resolution of touch: The sight of body parts increases tactile spatial sensitivity in two-point discrimination, and tactile spatial resolution in orientation judgement (Kennett et al., 2002). This effect of visual tuning of tactile processing occurs at an early stage in stimulus elaboration and perception. Indeed, transcranial magnetic stimulation over primary somatosensory cortex significantly reduces subjects' accuracy while viewing the hand, but not while viewing a neutral object at the same location (Fiorio and Haggard, 2005).

Visual disruption of temporal order judgement in touch: If your hands are crossed while you are being touched on both hands, you have difficulties in judging to which hand the first tactile stimulus was applied. This is due to the conflict between the body-centred spatial frame of reference and the external space, which both encode the location of tactile stimuli (Yamamoto and Kitazawa, 2001). However, congenitally blind people do not show any effect of hands crossing, in contrast with sighted and late-blind people (Röder et al., 2004). Vision puts spatial constraints on tactile processing, even if there is no visual information currently available.

Multimodal body distortion: In the Pinocchio experiment, the examiner induces illusory arm extension by tendon vibration (Lackner, 1988). If subjects at the same time hold their nose, they experience their nose as elongating by as much as $30 \mathrm{~cm}$. They feel that their arm is moving away from them, but still feel their nose. Since the head and the body are stationary, the combined sensory input is interpreted as the nose elongating. This experiment reveals that the representation of the body boundaries results from the integration of kinaesthetic, vestibular, proprioceptive, and tactile sources of information.

The multisensory nature of body representation has often been neglected by the philosophical tradition, which has focused more on contrasting the body with other physical objects, or bodies of other people (Merleau-Ponty, 1945; Bermúdez, 1998). However, these results (among others) show that bodily sensations must be understood against the background of a multimodal representation of the body.

5 These cross-modal effects may rely on two kinds of neural mechanisms. Electrophysiological studies in the monkey have shown in the premotor and the parietal cortex the existence of bimodal neurons that combine visual and somesthetic signals (Duhamel et al., 1997; Graziano, Cooke and Taylor, 2000). Furthermore, recent experiments suggest that back-projections from multimodal areas to unimodal areas may also play a role (Macaluso, Frith and Driver, 2000; Taylor-Clarke, Kennett and Haggard, 2002). Thus, primary areas may be unimodal in terms of their afferent information, yet they may be affected by other kinds of signals. We can no longer assume that the first levels of processing of sensory stimuli are encapsulated. As Driver and Spence (2000) said, cross-modal effects are 'beyond modularity'. 
This has some consequences for the sense of ownership. According to the spatial hypothesis, the sense of ownership is given by the spatial content of bodily sensations. However, the previous results indicate that bodily sensations are felt within a multimodal spatial representation of the body. ${ }^{6}$ One consequence of such a view is that the sense of ownership should be influenced by visual information. Botvinick and Cohen (1998) show that we can indeed alter the sense of ownership by artificially generating intermodal matching.

The subject's hand is hidden behind a screen and he sees instead a rubber hand directly in front of him. If both hands (the real and the fake ones) are stroked synchronously, the subject feels the touch not of the hidden brush on his real hand, but of the viewed brush on the rubber hand. Proprioceptive information decays rapidly when the hand stays stationary, while vision often predominates over other sensory modalities (Welch and Warren, 1986). It is therefore not surprising that the spatial content of tactile sensations relies more on vision than on proprioception. This alteration leads to the distortion of the sense of body location: when subjects were required to reach the hand that had been touched with their other hand, their movement was displaced rightward toward the rubber hand. Furthermore, most of them felt a sense of ownership toward the fake hand: 'I found myself looking at the dummy hand thinking it was actually my own' (Botvinick and Cohen, 1998, p. 756).

This assertion is not metaphorical as subjects showed stronger skin conductance reactions when the fake arm was injured after synchronous stimulation compared to asynchronous stimulation (Armel and Ramachandran, 2003). However, intermodal matching per se does not suffice to elicit the illusion. It has been shown that physical and postural similarities of the rubber hand with the real hand constrain the integration between vision and touch (Tsakiris and Haggard, 2005).

Without multimodal interaction, the phenomenon of the rubber hand would not have been possible. ${ }^{7}$ The sense of ownership results from the localisation of the tactile property within a body representation constructed on the basis of the information that is available to the subject (e.g. vision, touch and proprioception for most of the people). In the rubber hand illusion, the descriptive component of the tactile sensation is accurate, but not the spatial component. This interpretation is consistent with the spatial hypothesis. The fact that the sense of ownership results from bodily sensations - or at least from their spatial content-does not imply that it cannot be influenced by other sources of information, like vision.

6 Interestingly, asomatognosia does not result from a lesion of the primary somatosensory area, but from a lesion of the parietal area where multimodal integration happens.

7 In a brain imaging study, Ehrsson et al. (2004) show the involvement of the premotor cortex in the rubber hand illusion. The premotor cortex is known to play an important role for multimodal integration. Other studies in developmental psychology also emphasize the role of visuo-proprioceptive calibration of the body for the acquisition of the sense of ownership in children (Rochat, 1998). 


\subsection{Body Schema and Body Image}

According to the spatial hypothesis, the sense of ownership derives from the localisation of the bodily property within a spatial representation of the body. We argued that the boundaries of the body are not defined only on the basis of somatosensory perception, but rather on the basis of the integration between different sensory modalities such as proprioception, touch and vision. In case of conflict, the reliability and the intensity of each of these modalities determine which of them predominates over the others (van Beers et al., 2002). But is that all there is? Do we have here a full account of the sense of ownership?

It depends on which kind of spatial representation of the body we adopt. Indeed, there is not one single system of representation of the body. The body can be viewed from many different perspectives (e.g. semantic, emotional, spatial, motor, tactile, visual, proprioceptive, etc.) and described in terms of many pairs of opposing properties (e.g. conscious/unconscious, conceptual/non conceptual, dynamic/ static, innate/acquired). This diversity has led to a widely spread confusion about body representations. In order to clarify the conceptual landscape of the study of the body, it has been suggested that we need to distinguish between the body schema and the body image, a dichotomy that cuts across all the previous distinctions (Paillard, 1999; Gallagher, 2005).

Both are multimodal, although the body image puts more emphasis on vision, and the body schema on proprioception. The difference between the two body representations, as I see it, is mainly functional. We can draw a parallel here with the two visual pathways. Milner and Goodale (1995) distinguish two functions of vision, differentiating perception for action ('How') and perception for recognition ('What'). The dorsal visual pathway (infero-parietal) is dedicated to the agent's interactions with the object and the ventral visual pathway (infero-temporal) is dedicated to the semantic process of the properties of the object. This functional distinction is usually applied to external objects, but we can extend it to body perception. The body schema is for action and the body image is for identification (Paillard, 1999). The former represents an unconscious functional sensori-motor map of the body based on the information one needs in order to move one's own body (e.g. bodily posture and position, bodily constraints like size and strength of the limbs, kinematical constraints like the degree of freedom of the joints, etc). The latter is more heterogeneous. It groups all the information about the body necessary to make judgments about bodily properties. It includes a visuo-spatial map of the body, a semantic body representation and affective attitudes toward one's own body. The body schema is disturbed in apraxia (Sirigu et al., 1995). The body image (or at least the visuo-spatial body map) is disturbed in autotopagnosia (Sirigu et al., 1991).

Interestingly, either body representation can be used to locate tactile stimuli, as shown by the following double dissociation. Merleau-Ponty (1945) reported the case of Schneider who was unable to describe the position of his body and to localize tactile stimulations, but who was still able to scratch his leg where a mosquito had bitten him. Indeed, patients with 'numbsense' do not feel the tactile 
sensations but are still able to point where they have been touched (Rossetti et al., 1995). In contrast, deafferented patients can identify their body part, but have difficulties in reaching it, relying only a visuo-spatial body map (Paillard, 1999). It thus seems that we use both frames of reference: the spatial bodily framework of one's own actions and the detached map of one's own body. One needs to know how to reach the stimulated body part in order to be able to react to the sensation. But one also needs to be able to consciously identify the location. In the absence of one of the two systems, the other can partially compensate for its missing partner.

\subsection{The Role of Action}

Given this distinction, which of these two kinds of body representation is the basis of the sense of ownership? First, let me emphasize that I am not asking whether bodily sensations are part of the body image or of the body schema. Sensations are conscious, they constitute what Gallagher (2005) calls the 'body percept', and as such they are represented in the conscious body image. The relevant question here is about the spatial frame of reference of bodily sensations. Does the spatial content of bodily sensations relevant for the sense of ownership refer to the functional sensori-motor map of the body schema or to the visuo-spatial map of the body image? I would like to provide here some evidence in favour of the body schema.

A recent experiment shows that both afferent and efferent aspects of the moving body can influence the sense of ownership (Tsakiris et al., 2006). The rubber hand illusion was elicited on the sole basis of hand movements. Subjects did not see their hand, but saw a virtual hand projected in front of them. Both subjects' index finger and the index finger of the virtual hand moved up and down, either passively or actively. When the movements were synchronous, subjects felt that their own hand was closer to the virtual hand than when the movements were asynchronous ('proprioceptive drift'), like in the classical rubber hand illusion. In the passive condition, the illusion results from the integration between vision and proprioception. However, the active condition also involves efferent information signalling that the subject is moving his finger. Interestingly, the proprioceptive drift affected only the index finger in the passive condition (the other fingers were not felt closer to the virtual hand), while in the active condition, it affected the whole hand, and not only the moving finger. The effect was thus very local when based only on afferent information, and more global when based on afferent and efferent information. The authors concluded that efferent information influences the sense of ownership of the body by unifying the body as a whole. More generally, the representation of the body moving (whether passively or actively) plays an important role in the sense of ownership.

The study of prosthesis and tool use also argues in favour of the importance of the body schema. We saw at the beginning that amputees can feel the prosthesis as part of their body and react in the same way as if it was their own limb. Using a 
prosthesis involves motor adjustments. For instance, the weight of the prosthesis differs from the weight of a real limb. Therefore, in order to be able to properly use the prosthesis, the amputees have to integrate it in the functional map of the body schema. This hypothesis is confirmed by a recent brain imaging study that shows a shift of the centre of activation of the right posterior parietal cortex, indicating that the prosthesis is recognized as an alternative to the real hand (Maruishi et al., 2004). The prosthesis can be so well integrated that the person feels a sense of ownership towards it and may even forget that his limb was amputated:

And not too long ago I was lying in bed with my wife. I had removed my limb. We were eating some food I had cooked and I decided to get up and do the dishes. I reached over to take her plate, got up, and forgot I did not have my limb on. I fell on the floor, landing on the distal end of the stump (...) So, I guess I have reached a point where I am capable of such foolish acts as that and forget $m y$ leg was not on (Murray, 2004, p. 968, my emphasis). ${ }^{8}$

Similarly, neural representations of the body may be altered when using a tool to extend the subject's reaching space (for review see Maravita and Iriki, 2004). Studies of bimodal neurons in monkey parietal cortex have focused on the spatial relation between visual and tactile receptive fields. Tactile receptive fields on the hand gradually displaced their visual receptive field from an initial position near the hand towards the tip of the tool, as a function of tool learning. In human subjects with unilateral lesions, active use of a tool improved the cross-modal links between visual stimuli at the tool tip and tactile events at the hand (Maravita et al. 2002; Farne and Ladavas, 2000). These neural changes may underly the anecdotal observation that a person using a tool experiences tactile sensations at the tip of the tool (Descartes, 1637). Indeed, when you cross two sticks and deliver mechanical stimulation to the tip of the sticks, you have difficulties in making judgment of temporal order, in the same way than when you cross your hands (Yamamoto et al., 2005). In other words, the bodily property is located within a spatial representation that includes the tool, that is, within the body schema. The spatial content of bodily sensations has to be understood relatively to the body schema. According to the spatial hypothesis, the sense of ownership is given by the spatial content. Therefore, the sense of ownership is given by the body schema. ${ }^{9}$

If this is indeed the case, then we should find disturbances of the body schema in individuals who deny the ownership of their limb. As body schema deficits have

8 Similarly, after a few minutes of guiding the arm of a robot through a virtual reality apparatus, subjects reported that they felt 'in' the robot, such that one of them was afraid to drop an object for fear that it might fall on his foot, as if it were really his arm that held the object (Cole et al., 2000).

9 Anecdotally, we may notice here that one does not feel one's kidney as one's own, even during painful sensations. As far as I know, there is no case of disownership of internal organs. One reason may be that internal organs are not represented in the body schema. 
not been explicitly investigated in asomatognosia, we can only look for possible causes (e.g. lack of proprioceptive afference and attentional neglect) or consequences (e.g disruption of action control) of such deficits.

It has been suggested that the 'alien' feeling experienced by deafferented patients was linked to their inability to control their body at the beginning of their neuropathy (Gallagher and Cole, 1995). Indeed, they recovered a sense of ownership as soon as they were able to control their limbs. Similarly, a partial disruption of the body schema could explain the lack of the sense of ownership in individuals with asomatognosia. Interestingly, most of the patients suffering from asomatognosia are either paralyzed (like AF and SB for example) or also suffer from the anarchic hand syndrome (they cannot control their 'alien' hand). It would not be surprising therefore that their body schema is partly impaired. Elson and Schaüble (2004) reported an interesting case of ictal asomatognosia caused by epilepsy, which shows a direct correlation between the feeling of disownership and the inability to move the 'alien' limb. During his seizure, the patient felt his leg as alien and immediately fell. One possible interpretation is that the leg is not represented anymore in the sensori-motor map, which leads the patient both to fall and to feel that the leg does not belong to him.

The other alternative would be that asomatognosia is due to an impairment of the body image. However, there is some evidence that the visuo-spatial map is at least partly preserved. In Moro's study, AF and SB do not display any kind of autotopagnosia. They are able to name the different parts of his body and to point to any body part on a drawing or on the examiner's body. In a different study, when asked to draw their body, patients with asomatognosia both represented their 'alien' limb (Morin et al., 2002).

What about personal neglect, which is often associated with asomatognosia and which has been considered as a disorder of the body image (Gallagher, 2005)? I would like to suggest here another interpretation of personal neglect in terms of a disorder of the body schema. The classical Comb and Razor test of personal neglect investigates the explorative actions performed toward the left hemispace of the body, like brushing one's hair, shaving, or putting on make-up (McIntosh et al., 2000). The left body side is not the means of the action, but its goal. The ability to represent the body as a goal may be interpreted as part of the body schema, given the functional definition we previously gave. This would provide a further evidence of an impairment of the body schema in asomatognosia.

I suggest thus that the body schema in individuals with asomatognosia is disturbed. Consequently, the bodily properties that asomatognosics experience can no longer be appropriately localized within the impaired body schema. They feel the tactile stimulus, but they can localize it only by using a different spatial representation, such as the visuo-spatial map. However, this spatial representation is not specific to one's own body and thus, it does not suffice to provide the sense of ownership, as I will show in the next section. This claim needs of course more empirical evidence. One would have to explain why not all the patients with paralysis or body schema deficits suffer from asomatognosia. Unfortunately, I am 
not able to fully answer this question. All I could say is that it would be mistaken to assume that there is only one kind of deficit of the body schema (de Vignemont, 2006). One needs a better analysis of the components of the body schema in order to understand why asomatognosia happens sometimes and sometimes not. Yet, a specific impairment of the body schema remains a good candidate to understand why asomatognosics deny the ownership of their limb.

\subsection{Toward a Theory of the Sense of Ownership}

The spatial hypothesis of the sense of ownership can be articulated as follow:

a. The sense of ownership is grounded in the spatial content of bodily sensations.

b. The bodily property that is felt is localised within the body schema.

c. The sense of disownership can be accounted for by a disruption of the body schema.

d. The sense of ownership is grounded in the body schema.

However, something seems to be missing in such a view. The sense of ownership is first characterized by its first-personal perspective: this is $m y$ own body. Nowhere in the spatial hypothesis is there any reference to the first-person. How is the spatial content then able to ground the sense of ownership? This problem is already encountered by Martin's view, which reduces the sense of ownership to a spatial sense of boundaries. The solution lies at the level of the body schema, which features two key properties for the first-person perspective. First, the spatial hypothesis can work if and only if the spatial body representation is self-specific. It must be dedicated to the representation of one's own body. The visuo-spatial body map does not respect this constraint. It represents indeed both one's own body and the body of other people. For instance, people with autotopagnosia cannot locate body parts both on their own body and on the examiner's body. The spatial frame of reference is external and independent of whose body it is. Therefore, there is no guarantee that sensations represented in one's visuo-spatial map will be experienced as occurring in one's own body. In contrast, the boundaries of the sensori-motor functional map are the boundaries of one's own body in action. The body schema is not shared between the self and the other. It applies only to the subject's own body, to her posture, and to the size and the strength of her limbs. In this sense, it is first-personal. Not because it represents the body as one's own, but because it represents exclusively what counts as one's own body. Second, the body schema represents the acting body. Based on Wittgenstein's distinction in the Blue Book (1958), we may say that it represents the body as a subject, rather than as an object (Gallagher, 2003). The body schema does not take the body as an object to perceive and identify, in contrast with the body image. Following the functional distinction we previously gave, it represents the body in so far as it is a means to perform an action and to reach a goal. Body schema refers thus to the 
body as subject, as actor, rather than as object perceived. As such, it can base a first-personal perspective on the body.

We showed the first-personal dimension of the body schema. However, we are still far from a first-person phenomenology. Indeed, the body schema is most of the time unconscious. One may then ask how it can be the basis of the conscious feeling of ownership. However, I do not claim that the content of bodily sensations includes a first-person component. I would like here to adopt Dokic's solution to the problem of the phenomenology of the sense of ownership: the reference to the self is only implicit. I propose the following approximate description of bodily sensations:

Experience (a particular body part is $\mathrm{F}$ ), where $\mathrm{F}$ is localised in a first-personal sensori-motor body map.

Notice that the content itself does not include a reference to the body schema. The judgment 'my body part is F' makes explicit what is implicit in the bodily sensation. According to Dokic (2003), the transition from the experience to the judgment 'this is my body' would be 'primitively compelling' in Peacocke's (1992) sense. It means that the subject would find such transition to be self-evident independently of inferences from other premises and that the subject would not need to take the correctness of the transition to be answerable to anything else. The first-person phenomenology of the sense of ownership would thus consist in this 'compellingness' from the bodily sensation to the judgment of self-attribution.

Is this judgment immune to error through misidentification relative to the first person pronoun (Shoemaker, 1984)? The question is not whether it is me or someone else that feels that the legs are crossed. The question is whether I can know that it is my legs or someone else's legs on the basis of the same bodily sensation. According to Evans (1982), the proprioceptive system is such that I am assured that my own body is always the spatial source of the information that I proprioceptively receive. The normal way of gaining knowledge about one's own body through proprioception guarantees that proprioceptive self-ascriptions are immune to error through misidentification. Does asomatognosia challenge this claim? The same question was asked for the Anarchic hand (Marcel, 2003). Peacocke (2003) denies that the Anarchic Hand refutes the thesis of immunity to error with the following argument:

... the subject in Anarchic Hand knows, via proprioception and not by external visual or haptic perception, that someone's hand moves. But the subject does also know that it is his hand that moves. (Peacocke, 2003, p. 109)

However, if the patient suffers both from asomatognosia and Anarchic hand, as it can happen, then it seems that the conjunction of both syndromes may challenge the principle of immunity. But does the patient really know that it is not his hand that moves? Actually, he cannot know it, because it is not true. He can know that someone's hand is being touched through the normal ways of gaining tactile 
knowledge. But his experience of disownership cannot ground a judgment that someone else's hand is being touched. The patient can believe it of course. However, this belief will not be justified because the spatial content of the tactile sensation is not acquired by the normal ways of gaining self-knowledge. As we previously said, the visuo-spatial map does not allow one to make the distinction between one's own body and someone else's body, and therefore cannot ground any ownership judgment. Thus, asomatognosia and the Anarchic hand do not challenge the immunity principle. ${ }^{10}$

A final consequence of the spatial hypothesis is that it introduces two different temporalities: the temporality of the sensation and the temporality of the body schema. Bodily sensations are occurrent experiences. Each time I am touched, I have an experience that lasts approximately as long as the touch itself. In contrast, the body schema-even if it is flexible and dynamic - has a permanency that lasts more than each single bodily experience. In successive sensations, bodily properties are thus located within a single long-lasting body representation that binds them together. They are all about the same body, my own body. In this sense, the sense of ownership does not depend only on a transient sensation; it also depends on a more durable representation of the body. Therefore, the sense of ownership, however minimal and immersed it can be, always has a further dimension. It provides for the continuity of the bodily self.

\section{Conclusion}

One can experience one's limb as alien and believe that it belongs to someone else, despite the fact that one feels bodily sensations in the 'alien' limb. Does it mean that the sense of ownership is an additional quality over and above bodily sensations, resulting from a subpersonal mechanism dedicated to self-recognition? Not necessarily. I have argued here for a more parsimonious explanation. Asomatognosia reveals that the perceptual mode of bodily sensations does not suffice to provide the sense of ownership. However, it can be well explained by a spatial account of the sense of ownership. The sense of ownership arises from the spatial content of bodily sensations that localises bodily properties within the body schema. The sense of ownership thus derives from a sensori-motor map that defines the spatial boundaries of one's own body. These boundaries are flexible, depending on the integration of afferent and efferent information. By its relationship with the body schema, the sense of ownership of one's own body is linked to the sense of agency of one's own actions. These two aspects of self-consciousness are both grounded in action.

\section{Institut Jean-Nicod CNRS-ENS-EHESS}

10 However, my account of immunity differs from Evans' account. Ownership judgments are warranted by the spatial content of the sensations, and not by their perceptual mode. 


\section{References}

Aglioti, S., Peru, A. and Smania, N. 1999: Frames of references for mapping tactile stimuli in brain-damaged patients. Journal of Cognitive Neuroscience, 11, 67-79.

Armel, K.C. and Ramachandran, V.S. 2003: Projecting sensations to external objects: evidence from skin conductance response. Proceedings of the Royal Society London B Biological Sciences, 270, 1499-506.

Avenanti, A., Bueti, D., Galati, G. and Aglioti, S.M. 2005: Transcranial magnetic stimulation highlights the sensorimotor side of empathy for pain. Nature Neuroscience. 8, 955-60.

Ayer, A.J. 1963: Privacy. In his The Concept of a Person and Other Essays. New York: St. Martin's Press.

Bayne, T. and Levy, N. 2005: Amputees By Choice: Body Integrity Identity Disorder and the Ethics of Amputation. Journal of Applied Philosophy, 22, 75-86.

Bermúdez, J.L. 1998: The Paradox of Self-Consciousness. Cambridge, MA: MIT Press.

Bisiach, E., Rusconi, M.L. and Vallar, G. 1991: Remission of somatoparaphrenic delusion through vestibular stimulation. Neuropsychologia, 29, 1029-1031.

Blakemore, S.J., Bristow, D., Bird, G., Frith, C. and Ward, J. 2005: Somatosensory activations during the observation of touch and a case of vision-touch synaesthesia. Brain, 128, 1571-1583.

Botvinick, M. and Cohen, J. 1998: Rubber hands 'feel' touch that eyes see. Nature, 391, 756.

Bottini, G., Bisiach, E., Sterzi, R. and Vallar, G. 2002: Feeling touches in someone else's hand. Neuroreport, 13, 249-252.

Brion, S. and Jedynak, C.P. 1972: Troubles du transfert interhémisphérique callosal disconnection. A propos de trois observations de tumeurs du corps calleux. Le signe de la main étrangère. Revue Neurologique, 126, 257-266.

Cole, J. 1995: Pride and a Daily Marathon. Cambridge, MA: MIT Press.

Cole, J., Sacks, O. and Waterman, I. 2000: On the immunity principle: a view from a robot. Trends in Cognitive Sciences, 4, 167.

Decety, J. and Jackson, P.L. 2004: The functional architecture of human empathy. Behavioral and Cognitive Neuroscience Reviews, 3, 71-100.

Descartes, R. 1637/1958: Dioptric. New York: Modern Library.

Dokic, J. 2003: The sense of ownership: an analogy between sensation and action. In J. Roessler and N. Eilan (eds), Agency and Self-Awareness: Issues in Philosophy and Psychology. Oxford: Oxford University Press.

Driver, J. and Spence, C. 2000: Multisensory perception: beyond modularity and convergence. Current Biology, 10, R731-5.

Duhamel, J.R., Bremmer, F., BenHamed, S. and Graf, W. 1997: Spatial invariance of visual receptive fields in parietal cortex neurons. Nature, 389, 845-848.

Ehrsson, H.H., Spence, C. and Passingham, R.E. 2004: That's my hand! Activity in premotor cortex reflects feeling of ownership of a limb. Science, 305, 5685, 875-7.

Elson, L. and Schaüble, B.S. 2004: Ictal asomatognosia as a cause of epileptic falls. Neurology, 63, 2153-2154. 
Evans, G. 1982: The Varieties of Reference, ed. J. McDowell. Oxford: Oxford University Press.

Farne, A. and Ladavas, E. 2000: Dynamic size-change of hand peripersonal space following tool use. Neuroreport, 11, 1645-9.

Feinberg, T.E. 2002: Altered Egos How the Brain Creates the Self. New York: Oxford University Press.

Feinberg, T.E., Roane, D.M. and Cohen, J. 1998: Partial status epilepticus associated with asomatognosia and alien hand-like behaviours. Archive of Neurology, 55, 1574-1577.

Feinberg, T.E., DeLuca, J., Giacino J.T., Roane, D.M. and Solms, M. 2005: Right hemisphere pathology and the self: Delusional misidentification and reduplication. In T.E. Feinberg and J.P. Keenan (eds), The Lost Self: Pathologies of the Brain and Identity. New York: Oxford University Press.

Fiorio, M. and Haggard, P. 2005: Viewing the body prepares the brain for touch: effects of TMS over somatosensory cortex. European Journal of Neuroscience, 22, 773-7.

Fodor, J. 1983: The Modularity of Mind. Cambridge, MA: MIT Press.

Gallagher, S. 2003: Bodily self-awareness and object perception. Theoria et Historia Scientiarum: International Journal for Interdisciplinary Studies, 7, 1.

Gallagher, S. 2005: How the Body Shapes the Mind. New York: Oxford University Press.

Gallagher, S. and Cole, J. 1995: Body image and body schema in a deafferented subject. Journal of Mind and Behavior, 16, 369-390.

Gogol, N. 1835/1972: The nose. In Diary of a Madman and Other Stories. London: Penguin Books.

Graziano, M.S., Cooke, D.F. and Taylor, C.S. 2000: Coding the location of the arm by sight. Science, 290, 1782-6.

Gurwitsch, A. 1985: Marginal Consciousness. Athens, OH: Ohio University Press.

Kennett, S., Spence, C. and Driver, J. 2002: Visuo-tactile links in covert exogenous spatial attention remap across changes in unseen hand posture. Perceptual Psychophysiology, 64, 1083-94.

Keysers C., Wicker, B., Gazzola, V., Anton, J.L., Fogassi, L. and Gallese, V. 2004: A touching sight: SII/PV activation during the observation and experience of touch. Neuron, 42, 335-346.

Lackner, J.R. 1988: Some proprioceptive influences on the perceptual representation of body shape and orientation. Brain, 111, 281-297.

Leiguarda, R., Starkstein, S., Nogues, M., Berthier, M. and Arbelaiz, R. 1993: Paroxysmal alien hand syndrome. Journal of Neurology, Neurosurgery, and Psychiatry, 56, 788-792.

Macaluso, E., Frith, C. and Driver, J. 2000: Selective spatial attention in vision and touch: unimodal and multimodal mechanisms revealed by PET. Journal of Neurophysiology, 83, 3062-75.

Maravita, A., Spence, C., Sergent, C. and Driver, J. 2002: Seeing your own touched hands in a mirror modulates cross-modal interactions. Psychological Science, 13(4), 350-5.

Maravita, A. and Iriki, A. 2004: Tools for the body (schema). Trends in Cognitive Sciences, 8, 79-86. 
Marcel, A. 2003: The sense of agency: awareness and ownership of action. In J. Roessler and N. Eilan (eds), Agency and Self-Awareness: Issues in Philosophy and Psychology. Oxford: Oxford University Press.

Marchetti, C. and Della Salla, S. 1998: Disentangling the alien and the anarchic hand. Cognitive Neuropsychiatry, 3, 191-207.

Martin, M.G.F. 1995: Bodily awareness: a sense of ownership. In J. L. Bermúdez, A. Marcel and N. Eilan (eds), The Body and the Self. Cambridge, MA: MIT Press.

Maruishi, M., Tanaka, Y., Muranaka, H., Tsuji, T., Ozawa, Y., Imaizumi, S., Miyatani, M. and Kawahara, J. 2004: Brain activation during manipulation of the myoelectric prosthetic hand: a functional magnetic resonance imaging study. Neuroimage, 21, 1604-11.

McIntosh, R.D., Brodie, E.E., Beschin, N. and Robertson, I.H. 2000: Improving the clinical diagnosis of personal neglect: a reformulated comb and razor test. Cortex, 36, 289-292.

Melzack, R. 1990: Phantom limbs and the concept of a neuromatrix. Trends in Neuroscience, 13, 88-92.

Merleau-Ponty, M. 1945: Phénoménologie de la Perception. Paris: Gallimard.

Milner, D. and Goodale, M.A. 1995: The Visual Brain in Action. New York: Oxford University Press.

Morin, C., Durand, E., Marchal, F., Timsit, S., Manai, R., Pradat-Diehl, P. and Rancurel, G. 2002: Asomatognosia and oral drive: a psychoanalytical perspective. Annales de réadaptation et de médecine physique, 46, 12-23.

Moro, V., Zampini, M. and Aglioti, S.M. 2004: Changes in spatial position of hands modify tactile extinction but not disownership of contralesional hand in two right brain-damaged patients. Neurocase, 10, 437-443.

Murray, C.D. 2004: An interpretative phenomenological analysis of the embodiment of artificial limbs. Disability and Rehabilitation, 26, 963-973.

Paillard, J. 1999: Body schema and body image-A double dissoiation in deafferented patients. In G.N. Gantchev, S. Mori and J. Massion (eds), Motor Control, Today and Tomorrow. Sophia: Academic Publishing House.

Paqueron, X., Leguen, M., Rosenthal, D., Coriat, P., Willer, J.C. and Danziger, N. 2003: The phenomenology of body image distortions induced by regional anesthesia. Brain, 126, 702-712.

Peacocke, C. 1992: A Study of Concepts. Cambridge MA: MIT Press

Peacocke, C. 2003: Action: Awareness, Ownership, and Knowledge. In J. Roessler and N. Eilan (eds), Agency and Self-Awareness: Issues in Philosophy and Psychology. Oxford: Oxford University Press.

Rochat, P. 1998: Self-perception and action in infancy. Experimental Brain Research, 123, 102-109.

Röder, B., Rösler, F. and Spence, C. 2004: Early Vision Impairs Tactile Perception in the Blind. Current Biology, 14, 121-124.

Rossetti, Y., Rode, G. and Boisson, D. 1995: Implicit processing of somaesthetic information: a dissociation between where and how? Neuroreport, 6, 506-10.

Sacks, O. 1991. A Leg to Stand On. London: Picador. 
Schiff, N.D. and Pulver, M. 1999: Does vestibular stimulation activate thalamocortical mechanisms that reintegrate impaired cortical regions? Proceedings of the Royal Society London B Biological Sciences, 266, 421-423.

Senft, G. 1998: Body and Mind in the Trobriand Islands. Ethos, 26, 73-104.

Shoemaker, S. 1984: Self-reference and self-awareness. In his Identity, Cause and Mind. Cambridge: Cambridge University Press.

Sierra, M., Baker, D., Medford, N. and David, A.S. 2005: Unpacking the depersonalization syndrome: an exploratory factor analysis on the Cambridge Depersonalization Scale. Psychological Medicine, 35, 1-10.

Singer, T., Seymour, B., O’Doherty, J., Kaube, H., Dolan, R. J. and Frith, C.D. 2004: Empathy for pain involves the affective but not sensory components of pain. Science, 303, 5661, 1157-62.

Sirigu, A., Grafman, J., Bressler, K. and Sunderland, T. 1991: Multiple representations contribute to body knowledge processing. Evidence from a case of autotopagnosia. Brain, 114, 629-42.

Sirigu, A., Cohen, L., Duhamel, J.R., Pillon, B., Dubois, B., Agid, Y. and PierrotDeseilligny, C. 1995: Congruent unilateral impairments for real and imagined hand movements. Neuroreport, 6, 997-1001.

Smania, N. and Aglioti, S. 1995: Sensory and spatial components of somaesthetic deficits following right brain damage. Neurology, 45, 1725-30.

Spence, C. and Driver, J. (eds) 2004: Crossmodal Space and Crossmodal Attention. Oxford: Oxford University Press.

Taylor-Clarke, M., Kennett, S. and Haggard, P. 2002: Vision modulates somatosensory cortical processing. Current Biology, 12, 233-6.

Tsakiris, M. and Haggard, P. 2005: The rubber hand illusion revisited: visuotactile integration and self-attribution. Journal of Experimental Psychology: Human Perception and Performance, 31, 80-91.

Tsakiris, M., Prabhu, G. and Haggard, P. 2006: Having a body versus moving your body: how agency structures body-ownership. Consciousness and Cognition. 15, 423-32.

van Beers, R.J., Wolpert, D.M., Haggard, P. 2002: When feeling is more important than seeing in sensorimotor adaptation. Current Biology, 12, 834-7.

de Vignemont, F. 2006: Review of 'How the body shapes the mind' by Shaun Gallagher. Psyche, 12.

Welch, R.B. and Warren, D.H. 1986: Intersensory interactions. In L. Kaufman and J.P. Thomas (eds), Handbook of Perception and Human Performance, vol I, 1-25.

Wittgenstein, L. 1958: The Blue and Brown Books. Harper Collins Publishers, 1976.

Yamamoto, S. and Kitazawa, S. 2001: Reversal of subjective temporal order due to arm crossing. Nature Neuroscience, 4, 759-765.

Yamamoto, S., Moizumi, S. and Kitazawa, S. 2005: Referral of Tactile Sensation to the Tips of L-Shaped sticks. Journal of Neurophysiology, 93, 2856-2863. 